\title{
Does leisure time physical activity protect against low back pain? Systematic review and meta-analysis of 36 prospective cohort studies
}

\author{
Rahman Shiri, ${ }^{1}$ Kobra Falah-Hassani ${ }^{2}$
}

\begin{abstract}
- Additional material is published online only. To view, please visit the journal online (http://dx.doi.org/10.1136/ bjsports-2016-097352).

${ }^{1}$ Finnish Institute of Occupational Health, Helsinki, Finland

${ }^{2}$ Western University, London, Canada
\end{abstract}

\section{Correspondence to} Dr Rahman Shiri, Finnish Institute of Occupational Health, P.O. Box 40, Helsinki Fl-00251, Finland; rahman.shiri@ttl.fi

Accepted 1 May 2017 Published Online First 14 June 2017
CrossMark

To cite: Shiri R, FalahHassani K. Br J Sports Med 2017:51:1410-1418.

\begin{abstract}
Background There are plausible mechanisms whereby leisure time physical activity may protect against low back pain (LBP) but there have been no quality systematic reviews and meta-analyses of the subject. Objective This review aims to assess the effect of leisure time physical activity on non-specific LBP. Methods Literature searches were conducted in PubMed, Embase, Web of Science, Scopus and Google Scholar databases from their inception through July 2016. Methodological quality of included studies was evaluated. A random-effects meta-analysis was performed, and heterogeneity and publication bias were assessed.
\end{abstract}

Results Thirty-six prospective cohort studies ( $n=158475$ participants) qualified for meta-analyses. Participation in sport or other leisure physical activity reduced the risk of frequent or chronic LBP, but not LBP for $\geq 1$ day in the past month or past 6-12 months. Risk of frequent/chronic LBP was $11 \%$ lower (adjusted risk ratio (RR) $=0.89, \mathrm{Cl} 0.82$ to $0.97, \mathrm{I}^{2}=31 \%, \mathrm{n}=48520$ ) in moderately/highly active individuals, $14 \%$ lower ( $R R=0.86, \mathrm{Cl} 0.79$ to $0.94, \mathrm{I}^{2}=0 \%, \mathrm{n}=33032$ ) in moderately active individuals and $16 \%$ lower $(R R=0.84$, Cl 0.75 to $0.93,\left.\right|^{2}=0 \%, n=33032$ ) in highly active individuals in comparison with individuals without regular physical activity. For LBP in the past 1-12 months, adjusted RR was 0.98 (Cl 0.93 to $1.03, I^{2}=50 \%$, $\mathrm{n}=32654)$ for moderate/high level of activity, $0.94(\mathrm{Cl}$ 0.84 to $\left.1.05, I^{2}=3 \%, n=8549\right)$ for moderate level of activity and 1.06 (Cl 0.89 to $\left.1.25, I^{2}=53 \%, n=8554\right)$ for high level of activity.

Conclusions Leisure time physical activity may reduce the risk of chronic LBP by $11 \%-16 \%$. The finding, however, should be interpreted cautiously due to limitations of the original studies. If this effect size is proven in future research, the public health implications would be substantial.

\section{INTRODUCTION}

Low back pain (LBP) is a major global health problem. ${ }^{1}$ The prevalence of LBP in the past 12 months ranges between $25 \%$ and $40 \%^{2-5}$ and that of chronic LBP ranges between $4 \%$ and $25 \% .{ }^{46}$ Both the prevalence and incidence of LBP increase with age. ${ }^{267}$ Of lifestyle risk factors, smoking ${ }^{89}$ and obesity ${ }^{1011}$ are associated with increased risk of LBP and clinically verified sciatica. The role of leisure time physical activity in LBP is uncertain.

Leisure time physical activity is any bodily movement produced by the contraction of skeletal muscles that requires energy expenditure, such as walking or climbing stairs. ${ }^{12}$ Exercise is a specific form of leisure time physical activity that is a purposeful, planned and repetitive activity (eg, swimming, cycling or running), often with the goal of improving or maintaining physical fitness or other health benefits. ${ }^{12}$ In general, the intensity of leisure physical activity is light to moderate and that of exercise is moderate to strenuous. ${ }^{13}$ To date, several systematic reviews of observational studies found either no evidence for a relationship between leisure time physical activity and $\mathrm{LBP}^{14-17}$ or an increased risk of LBP in active individuals. ${ }^{18}$ Some systematic reviews showed no associations of leisure time physical activity with new episodes of LBP, ${ }^{15}$ LBP intensity, disability due to LBP or healthcare utilisation for LBP. ${ }^{16}$ Moreover, a systematic review found no evidence for an association between sedentary lifestyle or prolonged sitting during leisure time and LBP. ${ }^{19}$ On the other hand, another systematic review of observational studies found an increased risk of LBP in individuals performing strenuous physical activity during their leisure time. ${ }^{18}$

LBP is a common recurrent condition. There may be a reverse causation between leisure time physical activity and LBP. Individuals with LBP may limit their leisure time physical activities due to fear of pain. ${ }^{20}$ Individuals with LBP may also practice physical activities during leisure time due to medical recommendation. Many previous reviews ${ }^{141618}$ on leisure time physical activity combinedboth cross-sectional and cohort studies or combinedthe results of studies conducted exclusively in patients with LBP with the results of studies conducted in individuals without LBP. Cross-sectional studies are more prone to reverse causation bias than prospective cohort studies. ${ }^{21}$ In a meta-analysis of prospective cohort studies, ${ }^{22}$ we found that moderate to high level of physical activity during leisure time protects against the development of lumbar radicular pain, while in a meta-analysis of cross-sectional studies, ${ }^{22}$ we found an increased prevalence of lumbar radicular pain in active individuals compared with inactive participants. In the current systematic review and meta-analysis, we aimed to determine the effects of moderate and high levels of leisure time physical activity on different types of non-specific LBP. To limit reverse causation bias, we restricted our meta-analysis to prospective cohort studies only.

\section{METHODS}

This section is similar to that published in Shiri et al. $^{22}$ 


\section{Search strategy}

The PRISMA statement ${ }^{23}$ was used when developing the review protocol and meta-analysis. Comprehensive literature searches were conducted in PubMed, Embase, Scopus, Web of Science, Google Scholar and ResearchGate databases from their inception through July 2016, using predefined combinations of Medical Subject Headings terms (PubMed, see online Supplementary table 1), Emtree terms (Embase) and text words. There were no restrictions on language and age or sex of participants. The reference lists of included articles were also hand-searched for additional reports that might be relevant. The full text of studies on body mass index and smoking in relation to LBP were also looked at in case they reported results for leisure time physical activity.

\section{Inclusion and exclusion criteria}

The titles, abstracts and full texts of potentially relevant reports were screened to identify studies on the association of leisure time physical activity/inactivity with LBP. Only prospective cohort studies were eligible for inclusion in the review if they studied the effect of leisure time physical activity on non-specific LBP and at least some of the participants were free from LBP at baseline. We excluded studies on specific low back disorders such as sciatica, spinal stenosis or other spinal pathologies; studies that enrolled exclusively patients with LBP; studies on back pain combined with neck pain; studies on muscle-strengthening exercise and pregnancy-related LBP; and studies that did not report quantitative data to estimate a relative risk. The corresponding authors of eight studies ${ }^{24-31}$ were contacted for additional results; of them, six ${ }^{26-31}$ provided us with the new results.

\section{Outcome}

Following the outcomes used in the eligible studies, LBP outcomes of interest were as follows: LBP in the past month, LBP in the past 6-12 months, frequent (recurrent) LBP; chronic LBP; sick leave due to LBP and hospitalisation for LBP. Chronic LBP was defined as pain that lasts for 3 months or longer or pain for more than 30 days in the past 12 months. ${ }^{32}$

\section{Exposure}

Following the approach of studies that were eligible for inclusion, being physically active was defined as participation in a sport or other physical activity during leisure time, ${ }^{33-45}$ at least 1-2 times a week, ${ }^{5}{ }^{29-31} 46-50$ at least $0.5-1.0$ hour per week ${ }^{451}$ or being in the middle or upper third of the distribution of leisure time physical activity in a study sample. ${ }^{762852-55}$ Moderate level of physical activity was defined as participation in such activity 1-3 times a week, ${ }^{5293149} 1-3$ hours per week ${ }^{48}$ or being in the middle third of the distribution of leisure time physical activity in a study sample. ${ }^{7262853-55}$ High level of physical activity was defined as participation in leisure time physical activity, $\geq 3-4$ times per week,,$^{59314956}$ more than $2-4$ hours per week k $^{34355157}$ or being in the upper third of the distribution of such activity in a study sample. ${ }^{72628} 53-55$ We conducted meta-analyses comparing active versus inactive, moderate versus low activity, high activity versus low activity and high versus low or moderate activity.

\section{Quality assessment}

The methodological quality of the included studies was assessed independently by both reviewers using criteria adapted from the Effective Public Health Practice Project tool. ${ }^{58}$ We assessed four sources of bias: selection bias, performance bias, attrition bias and confounding (see online Supplementary table 2). Disagreements between raters were resolved through discussion.

\section{Meta-analysis}

From each study, we abstracted maximally adjusted risk estimates for the exposures and outcomes of interest, together with their 95\% CIs. For the prospective cohort studies that reported ORs, we converted ORs into risk ratios (RRs). ${ }^{59}$ For one study ${ }^{52}$ that did not report a CI for the HR, the SE was calculated using the following formula: $\mathrm{SE}=\log (\mathrm{HR}) / \mathrm{Z}$ value. ${ }^{60}$

Several studies 453842434852 used high or moderate/high level of physical activity as a comparison group and explored the associations of inactivity versus activity, low versus high and moderate versus high level of leisure time physical activity with LBP. An RR for high level of physical activity was calculated by inversing the RR for physical inactivity, and an RR for moderate level of physical activity by dividing the RR for moderate activity by the RR for inactivity. The SE of the estimate for physical inactivity was then used to calculate $95 \% \mathrm{CI}$ for high level of activity. For moderate level of activity, its own SE was used. SE and $95 \% \mathrm{CI}$ were calculated using natural logarithm of lower and upper limits of the CI. A reanalysis of data from two ${ }^{3154}$ of the included studies showed that this approach is valid.

Some studies reported two or more risk estimates for the associations of different types of sport activities with LBP, ${ }^{3649} 50$ two or more risk estimates for the association between physical activity and LBP for different follow-up periods ${ }^{24}$ or the association of physical activity with two or more outcomes. ${ }^{42}$ In these studies, some participants contributed data to more than one risk estimate. In this case, results were combined by a fixed-effect meta-analysis to give an overall pooled estimate for physical activity versus physical inactivity for the study. Moreover, the variance of the pooled estimate was corrected using a method suggested for combining multiple outcomes or multiple timepoints within a study. ${ }^{61}$

A fixed-effect meta-analysis was used to combine the independent subgroups of a single study and a random-effects meta-analysis was used to combine the estimates of different studies. ${ }^{60}$ The presence of heterogeneity across the studies was assessed by the $\mathrm{I}^{2}$ statistics. ${ }^{62}$ An $\mathrm{I}^{2}$ statistic less than $25 \%$ indicates small inconsistency and more than $50 \%$ indicates large inconsistency. ${ }^{63}$ Sensitivity analyses were performed with regard to the presence or absence of LBP at baseline, age of participants, adjustment for confounding factors and other methodological quality of included studies. Meta-regression ${ }^{64}$ was used to explore, whether studylevel covariates accounted for the observed heterogeneity and to test for differences in the RR between two or more subgroups. The influence of each individual study on the summary estimate was examined by repeating the meta-analysis with one study out at a time. A funnel plot was used for exploring publication bias, and Egger's regression test was used for examining funnel plot asymmetry. Furthermore, the trim and fill method was used to adjust for missing studies due to publication bias. ${ }^{656}$ Stata, V.13, was used for the meta-analyses.

\section{RESULTS}

\section{Study selection}

Our electronic searches of multiple databases identified 12434 publications (see online Supplementary figure 1). We screened the full text of 561 relevant publications on the association between physical activity and low back disorders. Of 52 eligible studies on LBP, we excluded five on back pain combined with neck pain, seven with insufficient data to estimate an RR, one 


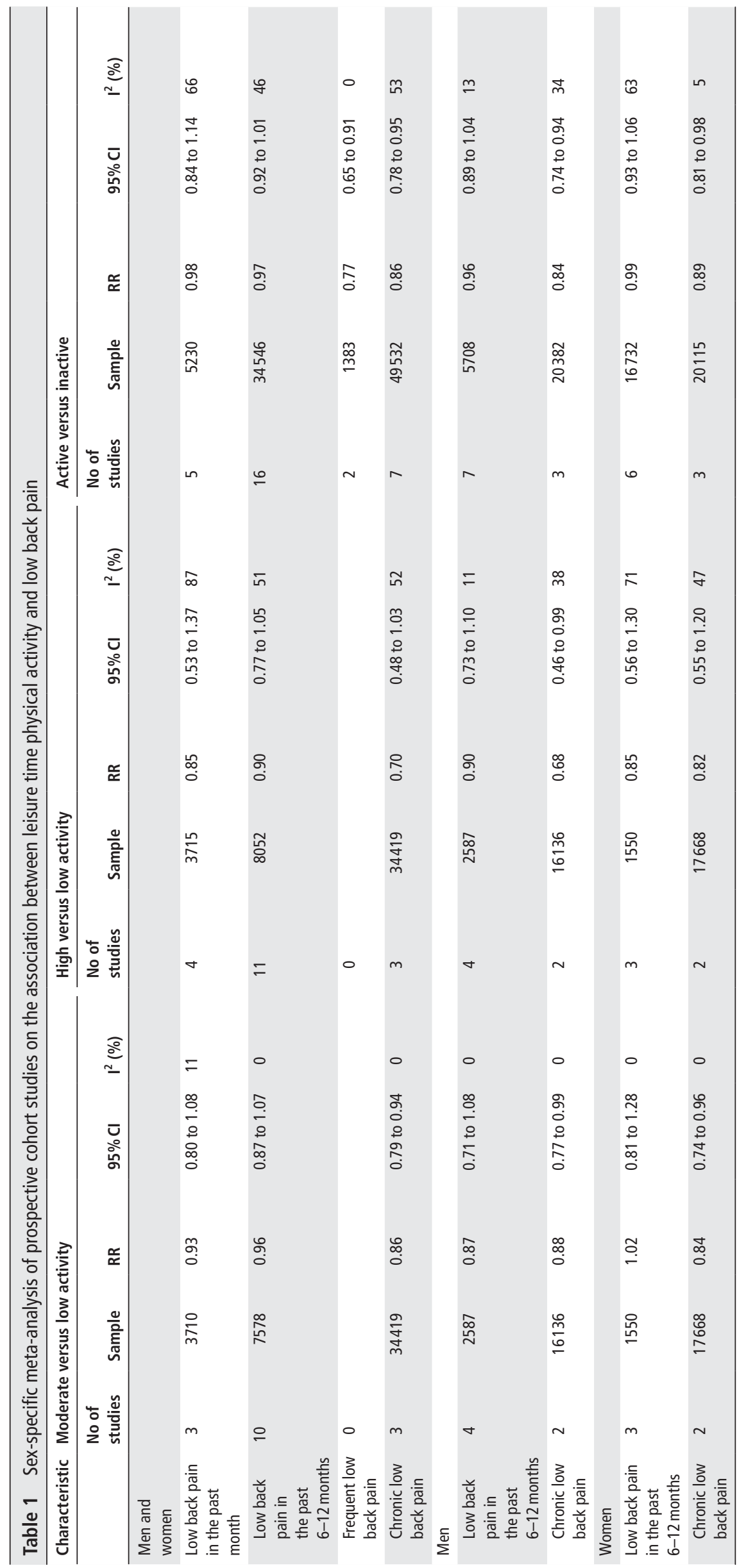


that assessed both physical activity and LBP at follow-up, one that combined leisure time physical activity with physical activity at work, one on muscle-strengthening exercises and, lastly, one in pregnant women (see online Supplementary figure 1).

Finally, 36 studies (37 reports, $n=158475$ participants) $)^{3-5} 72426-3133-5767$ on relationship between leisure time physical activity and LBP qualified for meta-analyses. The countries with the largest number of included studies comprised Finland $(n=7)$, Denmark $(n=6)$, UK $(n=4)$, USA $(n=4)$, Netherlands $(n=3)$, Norway $(n=3)$, Australia $(n=2)$ and Israel $(n=2)$. Canada, France, Italy, Hong Kong and Thailand provided one study each (see online Supplementary table 3).

\section{Leisure time physical activity}

Of 36 included studies, 26 inquired participation in organised sport or other leisure time physical activities and 10 studies $^{7} 242831333841434867$ participation in organised sport activities only (see online Supplementary table 3). Only two studies $^{2655}$ measured physical activity by an accelerometer, and only three studies ${ }^{28} 5254$ defined the levels of physical activity by using a physical activity index or metabolic equivalent of task (MET). Seven studies 27293034414749 defined the levels of physical activity based on frequency of weekly physical activity, five 2435434551 defined the levels based on number of hours per week, seven 343739425357 defined the levels based on number of hours and intensity of activity, four ${ }^{54648}$ defined the levels based on frequency and duration of activity, one ${ }^{31}$ defined the levels based on frequency and intensity of activity and one ${ }^{56}$ defined the levels based on frequency, duration and intensity of activity. Moreover, participation in sport or other leisure time physical activities was based on a yes/no question in six studies, 333638404467 which only one ${ }^{36}$ considered duration and one $^{44}$ considered intensity of activity.

\section{Methodological quality of included studies}

Eight studies were rated as having low risk of selection bias, 19 studies were rated as having moderate risk and nine were rated as having high risk of selection bias (see online Supplementary table 3). Nine studies were assessed as having low risk of performance bias, 23 were assessed as having moderate risk and four were assessed as having high risk of performance bias. Fifteen studies were rated as having low risk of attrition bias, 14 were rated as having moderate risk and seven were rated as having high risk. Twenty-eight studies controlled their risk estimates for some confounding factors such as age, sex and body mass index.

\section{Association between leisure time physical activity and low back pain}

Low back pain in the past month and low back pain in the past 6-12 months

Leisure time physical activity was neither associated with LBP in the past month (table 1 and figure 1 ) nor associated with LBP in the past 6-12 months (table 1 and figure 2). Compared with individuals with no regular physical activity, pooled RR of LBP for $\geq 1$ day in the past $1-12$ months was 0.98 (CI 0.93 to $1.03, \mathrm{I}^{2}=50 \%, 16$ studies, $\mathrm{n}=32654$ participants) for physically active individuals, 0.94 (CI 0.84 to $1.05, \mathrm{I}^{2}=3 \%$, eight studies, $\mathrm{n}=8549$ ) for moderately active individuals and 1.06 (CI 0.89 to $1.25, \mathrm{I}^{2}=53 \%$, nine studies, $\mathrm{n}=8554$ ) for highly active individuals in a meta-analysis of studies that controlled their risk estimates for some potential confounders (table 2). The association of leisure physical activity with LBP in the past 6-12 months did not differ between men and women (table 1).

Five studies ${ }^{34245767}$ on LBP in the past 6-12 months compared participants with high level of leisure time physical activity with those with low or moderate level of activity. The pooled
First author and year of publication

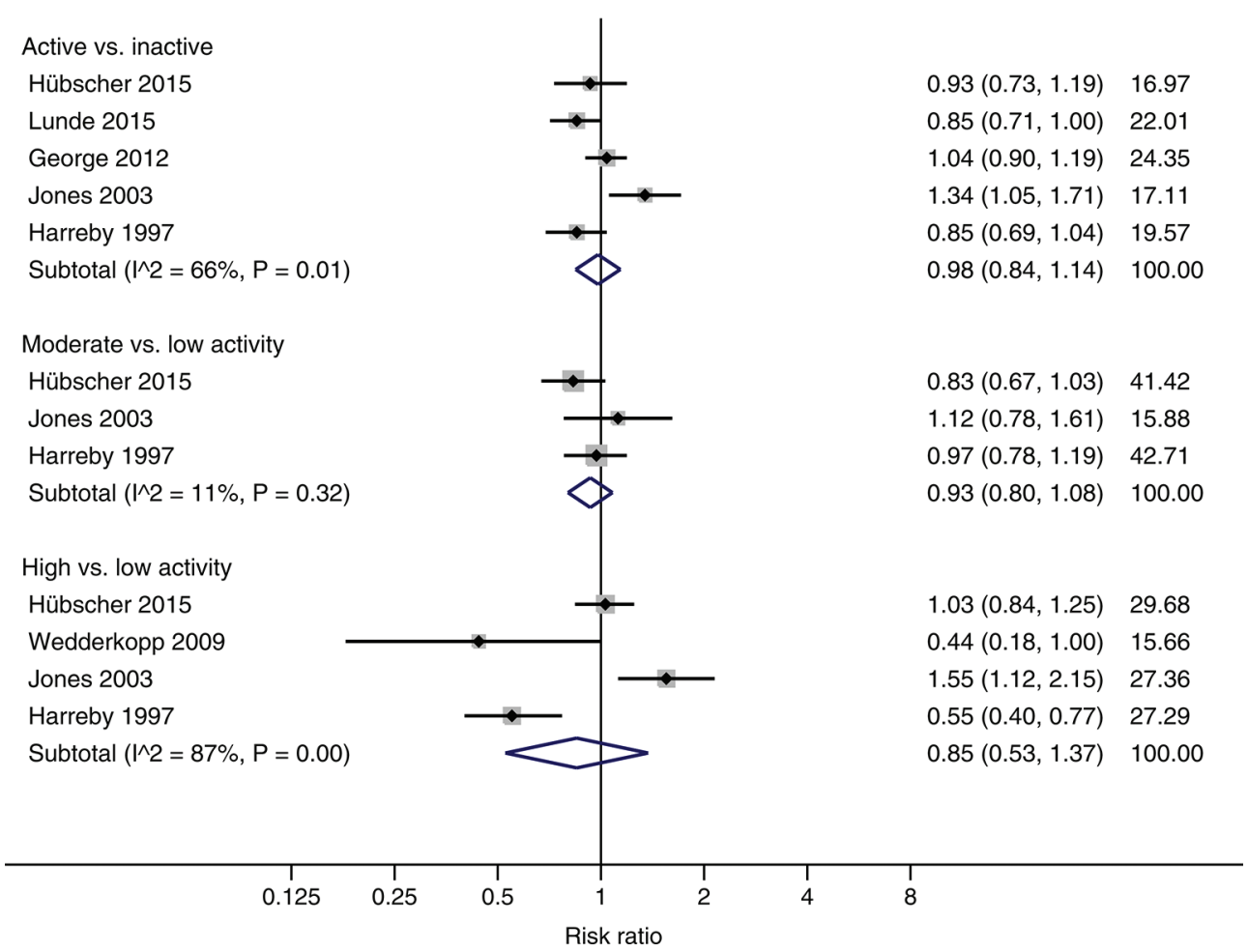

Figure 1 A meta-analysis of six studies on the effect of leisure time physical activity on low back pain in the past month. The size of the greyshaded area indicates the weight of each study. Horizontal lines show the $95 \%$ Cls. RR, risk ratio. 
RR across these five studies was 1.01 (CI 0.89 to $1.15, \mathrm{I}^{2}=7 \%$, $n=6151$, figure 2). Of the five studies, four ${ }^{345767}$ controlled their risk estimates for some confounding factors.

Frequent or chronic low back pain

Of two studies ${ }^{4647}$ on frequent LBP and seven ${ }^{4} 333437395152$ studies on chronic LBP, eight studies inquired participation in a sport or other leisure time physical activity and one ${ }^{33}$ participation in an organised sport activity only. Three studies ${ }^{47} 39$ defined the levels of leisure physical activity based on number of hours per week and intensity of activity, two ${ }^{34} 47$ were based on frequency of weekly physical activity, one ${ }^{51}$ was based on number of hours per week, one ${ }^{46}$ was based on frequency and duration of activity, one ${ }^{52}$ was based on a physical activity index and one ${ }^{33}$ was based on a yes/no question. Of two studies on frequent LBP, one ${ }^{46}$ defined it as experiencing at least 10 times LBP, while the other study ${ }^{47}$ did not report the frequency of pain. In the latter study, ${ }^{47}$ however, $61 \%$ of the participants had pain on a daily or weekly basis.

Participation in a sport or other leisure time physical activity was inversely associated with frequent or chronic LBP (table 1 and figure 3). In a meta-analysis of six studies that controlled their risk estimates for some potential confounders, the risk of frequent or chronic LBP was lower by $11 \%(\mathrm{RR}=0.89$, CI 0.82 to $0.97, \mathrm{I}^{2}=31 \%$, six studies, $\mathrm{n}=48520$, table 2 ) in physically active individuals, $14 \%\left(\mathrm{RR}=0.86\right.$, CI 0.79 to $0.94, \mathrm{I}^{2}=0 \%$, two studies, $\mathrm{n}=33032$ ) in moderately active individuals and by $16 \%$ $\left(\mathrm{RR}=0.84\right.$, CI 0.75 to $0.93, \mathrm{I}^{2}=0 \%$, two studies, $\left.\mathrm{n}=33032\right)$ in highly active individuals in comparison with individuals with no regular physical activity. All the six studies controlled the estimates for age, five controlled also for sex and body mass index, two controlled for smoking, ${ }^{37} 51$ one controlled for educational level, ${ }^{37}$ one controlled for job demands, ${ }^{34}$ one controlled for

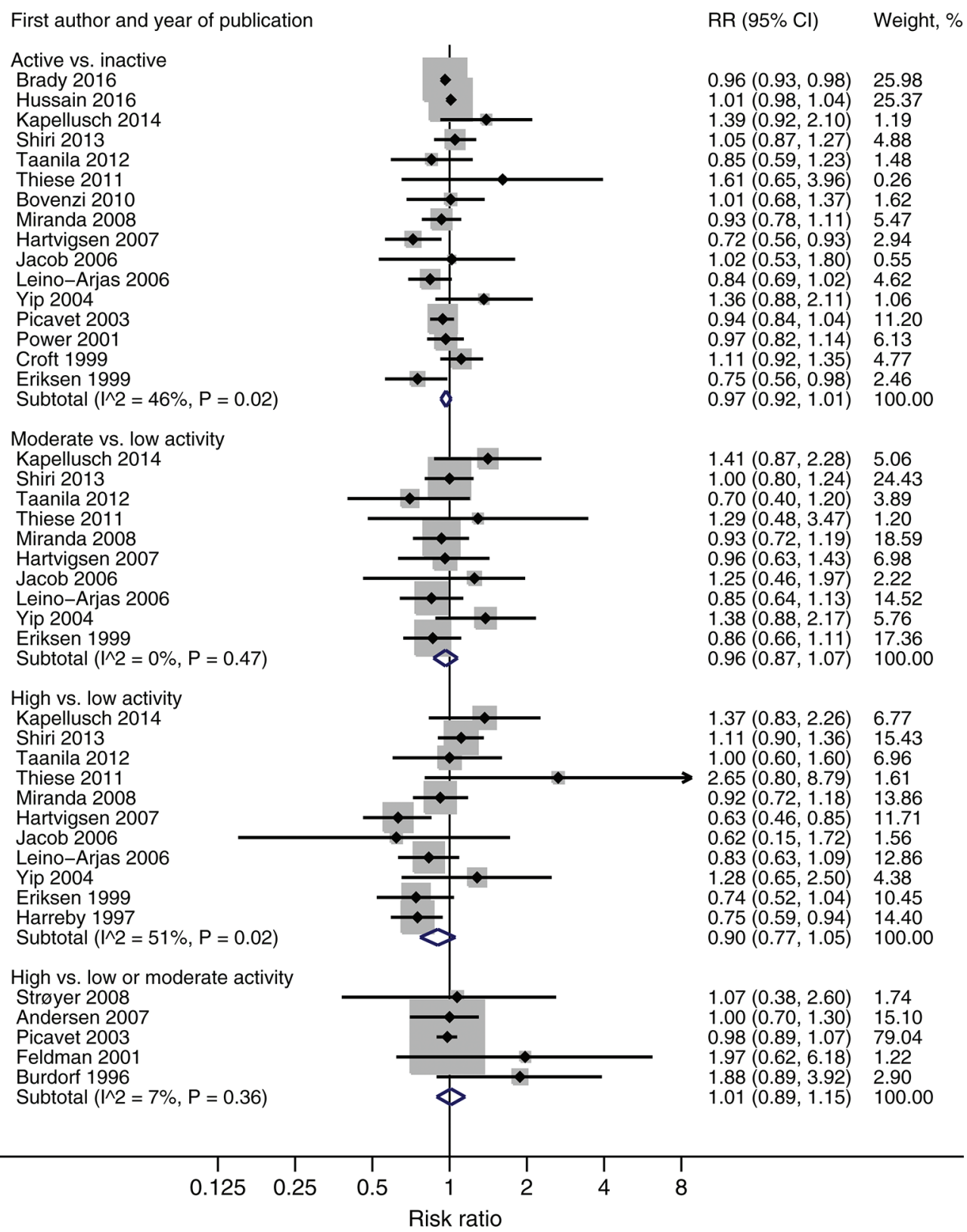

Figure 2 A meta-analysis of 21 studies on the effect of leisure time physical activity on low back pain in the past 6-12 months. The size of the greyshaded area indicates the weight of each study. Horizontal lines show the $95 \%$ Cls. RR, risk ratio. 


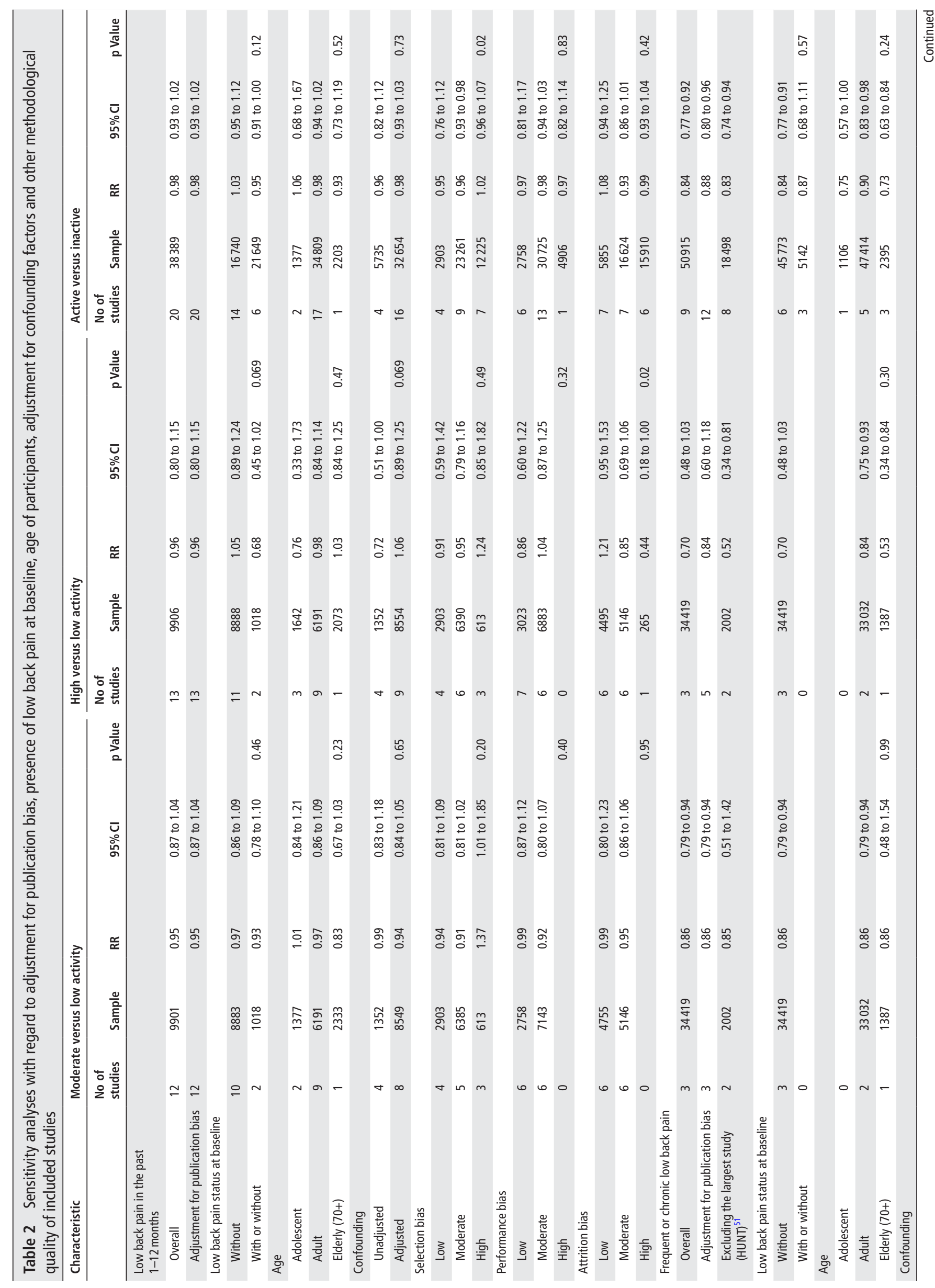




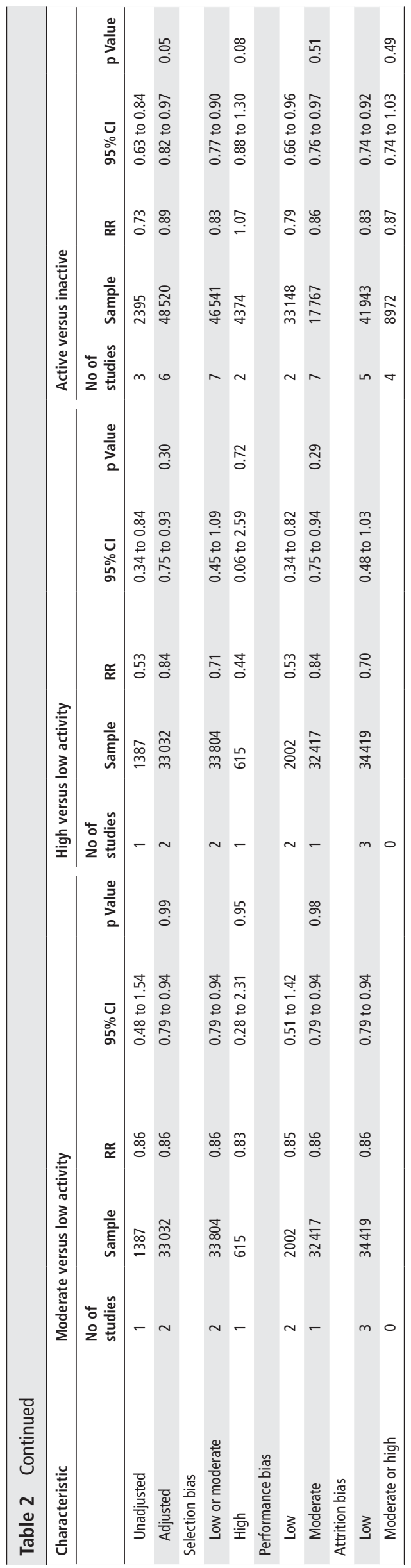

social class ${ }^{33}$ and one controlled for occupation. ${ }^{51}$ Excluding the largest study ${ }^{51}$ did not change the main results (table 2). The associations of moderate and moderate/high levels of physical activity with frequent or chronic LBP were statistically significant in both men and women, whereas the effect of high level of physical activity was statistically significant in men only ( $\mathrm{RR}=0.68$, CI 0.46 to 0.99 for men, and $\mathrm{RR}=0.82$, CI 0.55 to 1.20 for women). One ${ }^{39}$ of the included studies recruited a representative sample of twins and conducted a co-twin control design to control for environmental and genetic factors. The analysis of twins' pairs discordant for high level of physical activity at baseline showed a strong protective effect of physical activity against chronic LBP (see online Supplementary table 3).

\section{Sick leave and hospitalisation for low back pain}

Leisure time physical activity was not associated with sick leave or hospitalisation due to LBP. In both sexes combined, the pooled RR of sick leave due to LBP was 0.97 (CI 0.77 to $1.22, \mathrm{I}^{2}=0 \%$, two studies, $\mathrm{n}=5106$ ) for active compared with inactive. Pooled RR of hospitalisation due to LBP for participation in a sport club was 1.04 (CI 0.90 to 1.21) for males, 1.26 (CI 0.73 to 2.17) for females and 1.07 (CI 0.84 to $1.35, \mathrm{I}^{2}=50 \%$, two studies, $\mathrm{n}=66424)$ for both sexes.

\section{Heterogeneity and publication bias}

Overall, the level of heterogeneity was low to moderate. Heterogeneity across studies on frequent or chronic LBP was explained fully by selection bias and adjustment for confounding factors (tau-square $=0$, adjusted $\mathrm{R}^{2}=100 \%, \mathrm{I}^{2}$ residual $=0 \%$ ). The pooled RR across four studies 3337651 with low or moderate selection bias that controlled their risk estimates for some confounders was 0.86 (CI 0.82 to $0.91, \mathrm{I}^{2}=0 \%, \mathrm{n}=44146$ ) for active versus inactive. Heterogeneity across studies on LBP in the past 1-12 months was partly explained by selection bias.

Egger's test did not show publication bias for LBP in the past 1-12 months as well as for frequent or chronic LBP. For LBP in the past 1-12 months, $p$ value for Egger's test was 0.78 for 20 studies on active versus inactive (see online Supplementary figure 2), 0.12 for 12 studies on moderate versus low physical activity and 0.89 for 13 studies on high versus low physical activity. The trim and fill method did not impute any missing studies due to publication bias showing no or harmful effect for leisure time physical activity (table 2), whereas it imputed three missing studies showing protective effect for moderate level of physical activity on LBP in the past 1-12 months (see online Supplementary figure 3 ) and the pooled RR reduced to 0.92 (95\% CI 0.83 to 1.02) after adjustment for missing studies. $p$ Value for Egger's test was 0.38 for nine studies on frequent or chronic LBP for active versus inactive (see online Supplementary figure 4). The trim and fill method, however, imputed three missing studies due to publication bias (see online Supplementary figure 4), and the pooled RR increased to 0.88 (95\% CI 0.80 to 0.96 ) after adjustment for publication bias.

\section{Sensitivity analysis}

An adjustment for funnel plot asymmetry using the trim and fill method did not change the pooled estimates for both LBP in the past 1-12 months and frequent or chronic LBP (table 2). The pooled RR of frequent or chronic LBP for active versus inactive was stronger in elderly $(70+)$ than in adults (RR 0.73 vs 0.90 , table 2). However, all five studies ${ }^{43} 343751$ in adults controlled their risk estimates for some confounders, whereas none of the three studies ${ }^{39} 4752$ in elderly controlled for any confounding 


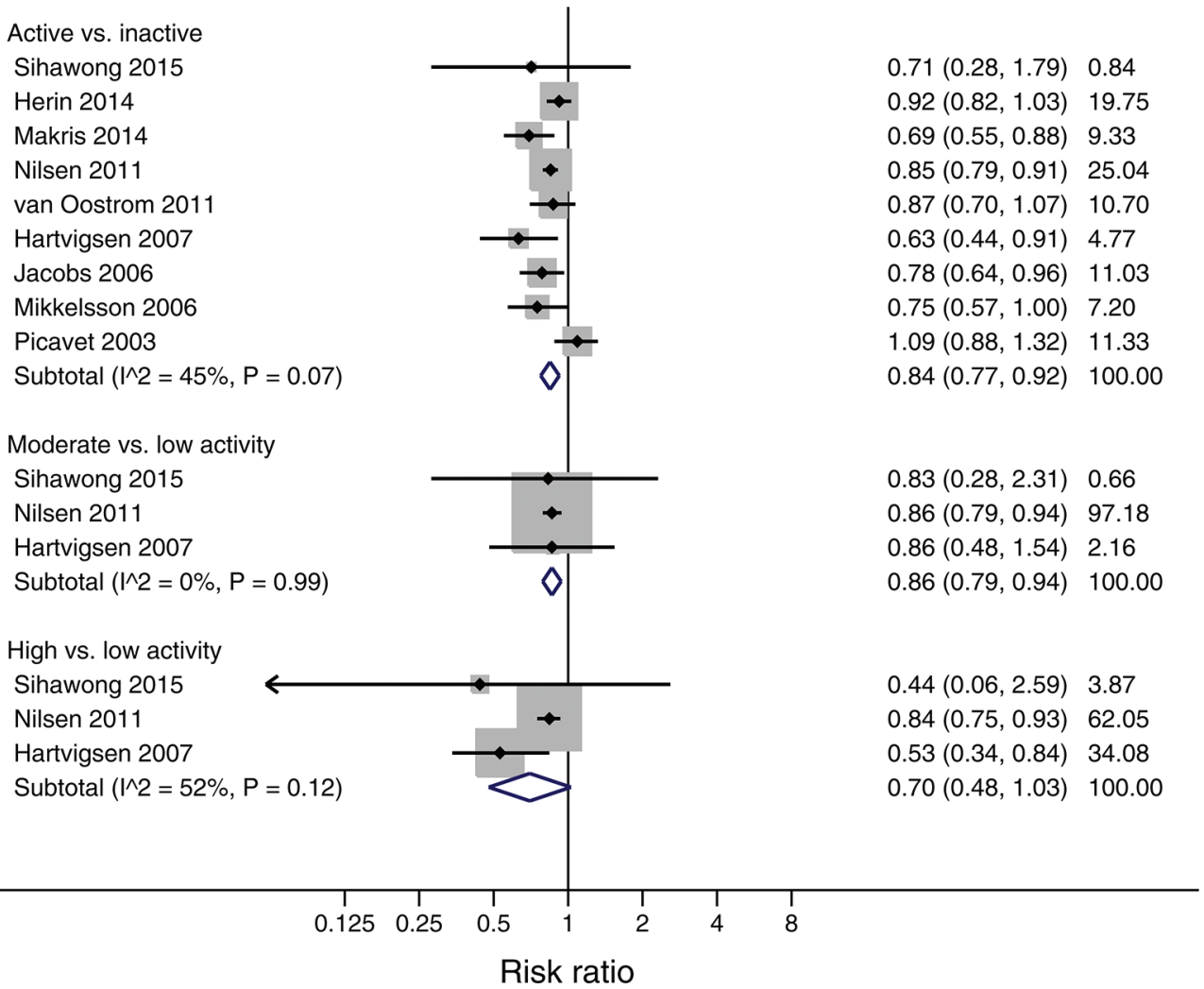

Figure 3 A meta-analysis of nine studies on the effect of leisure time physical activity on frequent or chronic low back pain. The size of the greyshaded area indicates the weight of each study. Horizontal lines show the $95 \%$ Cls. RR, risk ratio.

factor. The studies that did not adjust their risk estimates for any confounding factor reported a stronger inverse association between physical activity and frequent or chronic LBP than the studies that controlled their estimates for some confounders. Other methodological quality of the included studies had no impact on the pooled estimates (table 2).

Of the six studies on frequent or chronic LBP that controlled the estimates for some confounding factors, only two ${ }^{3351}$ were rated as having low risk of both selection bias and attrition bias. The combined RR across these two studies was 0.87 (CI 0.81 to $0.94, \mathrm{I}^{2}=25 \%, \mathrm{n}=39210$ ) for active compared with inactive. Both studies controlled the estimate for age, sex and body mass index; one $\mathrm{e}^{33}$ controlled further for social class and one $\mathrm{F}^{51}$ controlled for occupation and smoking. However, one ${ }^{51}$ of the studies defined the levels of leisure time physical activity based on the number of hours spent on physical activity per week, and the other one $\mathrm{e}^{33}$ was based on a yes/no question only.

\section{DISCUSSION}

This meta-analysis suggests that moderate to high level of physical activity during leisure time protects against frequent or chronic LBP by $11 \%-16 \%$. However, leisure time physical activity is not associated with changes in risk of LBP in the past month or in the past 6-12 months.

\section{Chronic low back pain}

In the current meta-analysis, the studies on chronic LBP, except one, included participants free from chronic LBP at baseline in the analysis. The possibility of reverse causation bias is therefore less likely. However, individuals may have had LBP before entering into the studies. Individuals with a history of frequent or chronic LBP are more likely to become less active during their leisure time than those without $\mathrm{LBP}^{20}{ }^{20}$ Furthermore, a history of LBP is a strong predictor of future $\mathrm{LBP}^{34}$ In line with the current review, in a meta-analysis of prospective cohort studies, we found that high level of leisure time physical activity reduces the risk of lumbar radicular pain by $16 \% .^{22}$ Physical activity during leisure time may have a role in preventing chronic LBP.

The mechanisms underlying the preventive effect of physical activity against chronic LBP are unclear. Physical activity interventions for LBP are commonly proposed to work by changing things like posture and muscle activation. Yet, there is a lack of evidence linking the effects of exercise in LBP to changes in the musculoskeletal system. ${ }^{68-70}$ However, changes are seen in variables like fear, catastrophising, self-efficacy and beliefs. ${ }^{71} 72$ There is now strong evidence that LBP is best understood from a biopsychosocial perspective as it can involve combinations of different psychological, social, lifestyle and physical factors. ${ }^{73}$ Therefore, future research on physical activity interventions for LBP should involve measuring an array of biopsychosocial variables to further our understanding of mechanisms of effect of physical activity in this population.

\section{Other types of low back pain}

Leisure time physical activity has no preventive effect on LBP for $\geq 1$ day in the past month or LBP in the past 6-12 months. LBP for a day within a year is a common condition with a prevalence of $25 \%-40 \%$ in the general population. ${ }^{2-5}$ This type of outcome is non-specific and can be a part of a healthy lifestyle. We also found no association between leisure time physical activity and sick leave or hospitalisation due to LBP. The current meta-analysis had low statistical power for sick leave or hospitalisation. There 
were only two studies on hospitalisation and two studies on sick leave due to LBP. One ${ }^{49}$ of these studies was large $(n=57408)$, but only $1.1 \%$ of the study population had been hospitalised for LBP during 11 years follow-up. Furthermore, the studies on sick leave or hospitalisation looked at different types of sport activities and did not consider all leisure activities using a physical activity index or MET. Of the four studies, one ${ }^{41}$ defined inactive as practising physical activity $\leq 2$ times per week and one ${ }^{43}$ as $<3$ hours per week. This misclassification can underestimate the effect of leisure time physical activity on sick leave or hospitalisation due to LBP.

\section{Limitations}

The current meta-analysis had some limitations. The included studies recruited various population groups. Due to a small number of cohort studies conducted in adolescents and elderly people, this meta-analysis had a low statistical power to determine whether age modifies the association between leisure time physical activity and LBP. In older people, inactivity is more likely to be a consequence of chronic LBP. ${ }^{17}$ Our sensitivity analysis, however, showed similar association in adults and elderly people. Furthermore, 22\% of included studies did not control their risk estimates for any confounding factor. The pooled estimates, however, changed only slightly after excluding the studies that reported unadjusted estimates only. Of studies on frequent or chronic LBP, only very few controlled the estimates for smoking and occupational physical and psychosocial risk factors, and none controlled for depression and fear avoidance beliefs. Individuals with physically strenuous jobs, ${ }^{74}$ smokers $^{74}$ and those with depression ${ }^{75}$ are less likely to engage in leisure time physical activity than individuals with non-manual jobs, never smokers or those without depression. Occupational factors, ${ }^{76}$ smoking ${ }^{8}$ and depression ${ }^{77}$ are also risk factors for LBP; thus, not adjusting the estimates for these known determinants of both leisure time physical activity and LBP may have led to overestimation of protective effect of leisure physical activity on frequent or chronic LBP.

The included studies classified the levels of leisure time physical activity in different ways and used different cutpoints for moderate and high levels of leisure time physical activity. Several studies classified individuals with 2-3 hours per week physical activity during leisure time as inactive. This type of exposure misclassification can lead to underestimation of an association between leisure time physical activity and LBP. We recalculated RRs where possible to compare moderate versus low physical activity and high versus low physical activity. However, some studies allowed classification to active versus inactive only. These studies did not, therefore, contribute to meta-analyses comparing moderate with low physical activity and high with low physical activity.

Only a few studies objectively measured leisure time physical activity, computed total weekly leisure physical activity or considered physical activity during commuting to work. Physical activity assessment methods may have a significant impact on the association between leisure time physical activity and LBP. To date, there is little information on the selection of an appropriate physical activity assessment tool for large epidemiological studies. ${ }^{78}$ However, self-reports of physical activity can overestimate as well as underestimate the levels of physical activity. ${ }^{79} 80$ Individuals with LBP may also underestimate or overestimate their level of physical activity. ${ }^{80} 81$ It is therefore unclear whether using self-reported measures of physical activity have led to underestimation or overestimation of the observed association between leisure time physical activity and LBP.

\section{What is already known on this topic?}

- The role of leisure time physical activity in low back pain is uncertain.

- Previous studies have reported inconsistent results regarding the relationship between leisure time physical activity and non-specific low back pain.

\section{What this study adds?}

- Leisure time physical activity has no preventive effect on low back pain for $>1$ day in the past month or past 6-12 months.

- Leisure time physical activity may provide modest protection against frequent or chronic low back pain.

- The protective effect of leisure physical activity on chronic low back pain is seen in both men and women as well as in both adults and older people.

\section{Implications and recommendations for research}

Consistent assessments of both physical activity and LBP across studies are needed to understand the effect of physical activity on LBP. In addition to new episodes of LBP, future prospective studies should also explore the effect of leisure time physical activity on LBP severity, chronicity and disability. Studies on LBP should consider not only all dimensions of physical activity (type, frequency, duration and intensity) but also all domains of physical activity (leisure time, household, commuting and work). The levels of leisure time physical activity should be defined based on total weekly moderate-intensity physical activity and vigorous-intensity physical activity. Furthermore, future studies should control the association between physical activity and LBP for all known confounding factors, including age, sex, education, social class, smoking, body mass index, occupational physical and psychosocial factors, depression and fear avoidance beliefs.

\section{CONCLUSIONS}

Leisure time physical activity may have a modest protective effect on the development of frequent or chronic LBP. The results, however, should be interpreted cautiously due to limitations of the original studies.

Correction notice This paper has been amended since it was published Online First. Owing to a scripting error, some of the publisher names in the references were replaced with 'BMJ Publishing Group'. This only affected the full text version, not the PDF. We have since corrected these errors and the correct publishers have been inserted into the references.

Acknowledgements This study was supported by the Finnish Ministry of Education and Culture (grant no 253715). We thank Professor Massimo Bovenzi, ${ }^{30}$ Dr Tamar Jacob, ${ }^{28}$ Dr Jay M Kapellusch, ${ }^{29}$ Mr Lars-Kristian Lunde, ${ }^{27}$ Dr Henri Taanila ${ }^{31}$ and Dr Matthew S Thiese ${ }^{26}$ for providing us with additional results.

Contributors RS developed the review protocol and conducted the literature searches. Both authors screened the eligible studies and rated the quality of included studies. RS extracted the data, performed the meta-analyses, interpreted the results and drafted the manuscript.

Funding The Finnish Ministry of Education and Culture (grant no 253715).

Competing interests None declared.

Provenance and peer review Not commissioned; externally peer reviewed.

(c) Article author(s) (or their employer(s) unless otherwise stated in the text of the article) 2017. All rights reserved. No commercial use is permitted unless otherwise expressly granted. 


\section{REFERENCES}

1 Global Burden of Disease Study 2013 Collaborators. Global, regional, and national incidence, prevalence, and years lived with disability for 301 acute and chronic diseases and injuries in 188 countries, 1990-2013: a systematic analysis for the Global Burden of Disease Study 2013. Lancet

2015;386:743-800

2 Shiri R, Solovieva S, Husgafvel-Pursiainen K, et al. The association between obesity and the prevalence of low back pain in young adults: the cardiovascular risk in Young Finns Study. Am J Epidemiol 2008;167:1110-9.

3 Andersen JH, Haahr JP, Frost P. Risk factors for more severe regional musculoskeletal symptoms: a two-year prospective study of a general working population. Arthritis Rheum 2007:56:1355-64.

4 Picavet HS, Schuit AJ. Physical inactivity: a risk factor for low back pain in the general population? J Epidemiol Community Health 2003;57:517-8.

5 Eriksen W, Natvig B, Bruusgaard D. Smoking, heavy physical work and low back pain: a four-year prospective study. Occup Med 1999;49:155-60.

6 Meucci RD, Fassa AG, Faria NM. Prevalence of chronic low back pain: systematic review. Rev Saude Publica 2015;49.

7 Jones GT, Watson KD, Silman AJ, et al. Predictors of low back pain in British schoolchildren: a population-based prospective cohort study. Pediatrics 2003;111:822-8.

8 Shiri R, Karppinen J, Leino-Arjas $\mathrm{P}$, et al. The association between smoking and low back pain: a meta-analysis. Am J Med 2010;123:87.e7-87.e35.

9 Shiri R, Falah-Hassani K. The effect of smoking on the risk of sciatica: a meta-analysis. Am J Med 2016;129:64-73. e20.

10 Shiri R, Karppinen J, Leino-Arjas P, et al. The association between obesity and low back pain: a meta-analysis. Am J Epidemiol 2010;171:135-54.

11 Shiri R, Lallukka T, Karppinen J, et al. Obesity as a risk factor for sciatica: a metaanalysis. Am J Epidemiol 2014;179:929-37.

12 Booth FW, Roberts CK, Laye MJ. Lack of exercise is a major cause of chronic diseases. Compr Physiol 2012;2:1143-211.

13 Ainsworth BE, Haskell WL, Herrmann SD, et al. 2011 Compendium of Physical Activities: a second update of codes and MET values. Med Sci Sports Exerc 2011;43:1575-81.

14 Sitthipornvorakul E, Janwantanakul P, Purepong N, et al. The association between physical activity and neck and low back pain: a systematic review. Eur Spine J 2011;20:677-89.

15 Bakker EW, Verhagen AP, van Trijffel E, et al. Spinal mechanical load as a risk factor for low back pain: a systematic review of prospective cohort studies. Spine 2009;34:E281-93.

16 Hendrick P, Milosavljevic S, Hale L, et al. The relationship between physical activity and low back pain outcomes: a systematic review of observational studies. Eur Spine J 2011;20:464-74.

17 Griffin DW, Harmon DC, Kennedy NM. Do patients with chronic low back pain have an altered level and/or pattern of physical activity compared to healthy individuals? A systematic review of the literature. Physiotherapy 2012;98:13-23.

18 Heneweer H, Staes F, Aufdemkampe G, et al. Physical activity and low back pain: a systematic review of recent literature. Eur Spine J 2011;20:826-45.

19 Chen SM, Liu MF, Cook J, et al. Sedentary lifestyle as a risk factor for low back pain: a systematic review. Int Arch Occup Environ Health 2009:82:797-806.

20 Leeuw M, Goossens ME, Linton SJ, et al. The fear-avoidance model of musculoskeletal pain: current state of scientific evidence. J Behav Med 2007:30:77-94.

21 Detels R, Gulliford M, Abdool Karim Q, et al. Oxford Textbook of Global Public Health: Oxford University Press, 2015

22 Shiri R, Falah-Hassani K, Viikari-Juntura E, et al. Leisure-time physical activity and sciatica: a systematic review and meta-analysis. Eur J Pain 2016;20:1563-72

23 Moher D, Liberati A, Tetzlaff J, et al. PRISMA Group. Preferred reporting items for systematic reviews and meta-analyses: the PRISMA statement. Ann Intern Med 2009;151:264-9.

24 Feldman DE, Shrier I, Rossignol M, et al. Risk factors for the development of low back pain in adolescence. Am J Epidemiol 2001;154:30-6.

25 Mitchell T, O'Sullivan PB, Burnett A, et al. Identification of modifiable personal factors that predict new-onset low back pain: a prospective study of female nursing students. Clin J Pain 2010;26:275-83

26 Thiese MS, Hegmann KT, Garg A, et al. The predictive relationship of physical activity on the incidence of low back pain in an occupational cohort. J Occup Environ Med 2011;53:364-71.

27 Lunde LK, Koch M, Hanvold TN, et al. Low back pain and physical activity - a 6.5 year follow-up among young adults in their transition from school to working life. BMC Public Health 2015:15:1115

28 Jacob T. Low back pain incident episodes: a community-based study. Spine J 2006;6:306-10

29 Kapellusch JM, Garg A, Boda S, et al. Association between lifting and use of medication for low back pain: results from the Backworks Prospective Cohort Study. J Occup Environ Med 2014;56:867-77.
30 Bovenzi M. A longitudinal study of low back pain and daily vibration exposure in professional drivers. Ind Health 2010;48:584-95.

31 Taanila HP, Suni JH, Pihlajamäki HK, et al. Predictors of low back pain in physically active conscripts with special emphasis on muscular fitness. Spine J 2012:12:737-48

32 Griffith LE, Hogg-Johnson S, Cole DC, et al. Low-back pain definitions in occupational studies were categorized for a meta-analysis using Delphi consensus methods. J Clin Epidemiol 2007;60:625.e1-625.e23.

33 Herin F, Vézina $M$, Thaon I, et al. Predictive risk factors for chronic regional and multisite musculoskeletal pain: a 5-year prospective study in a working population. Pain 2014;155:937-43.

34 Sihawong R, Sitthipornvorakul E, Paksaichol A, et al. Predictors for chronic neck and low back pain in office workers: a 1-year prospective cohort study. J Occup Health 2016:58:16-24.

35 Harreby M, Hesselsøe G, Kjer J, et al. Low back pain and physical exercise in leisure time in 38-year-old men and women: a 25-year prospective cohort study of 640 school children. Eur Spine J 1997;6:181-6.

36 Croft PR, Papageorgiou AC, Thomas E, et al. Short-term physical risk factors for new episodes of low back pain. Prospective evidence from the South Manchester Back Pain Study. Spine 1999:24:1556-61.

37 van Oostrom SH, Monique Verschuren WM, de Vet HC, et al. Ten year course of low back pain in an adult population-based cohort — the Doetinchem cohort study. Eur J Pain 2011;15:993-8.

38 Power C, Frank J, Hertzman C, et al. Predictors of low back pain onset in a prospective British study. Am J Public Health 2001;91:1671-8.

39 Hartvigsen J, Christensen K. Active lifestyle protects against incident low back pain in seniors: a population-based 2-year prospective study of 1387 Danish twins aged 70-100 years. Spine 2007;32:76-81.

40 George SZ, Childs JD, Teyhen DS, et al. Predictors of occurrence and severity of first time low back pain episodes: findings from a military inception cohort. PLoS One 2012; 7:e30597.

41 Rivinoja AE, Paananen MV, Taimela SP, et al. Sports, smoking, and overweight during adolescence as predictors of sciatica in adulthood: a 28-year follow-up study of a birth cohort. Am J Epidemiol 2011:173:890-7.

42 Hemingway $H$, Shipley M, Stansfeld S, et al. Are risk factors for atherothrombotic disease associated with back pain sickness absence? The Whitehall II Study. J Epidemiol Community Health 1999;53:197-203.

43 Müller CF, Monrad T, Biering-Sørensen F, et al. The influence of previous low back trouble, general health, and working conditions on future sick-listing because of low back trouble. A 15-year follow-up study of risk indicators for self-reported sick-listing caused by low back trouble. Spine 1999;24:1562-70.

44 Brady SRE, Monira Hussain S, Brown WJ, et al. Predictors of back pain in middle-aged women: data from the Australian Longitudinal Study of Women's Health. Arthritis Care Res 2017:69:709-16.

45 Hussain SM, Urquhart DM, Wang Y, et al. Associations between television viewing and physical activity and low back pain in community-based adults: a cohort study. Medicine 2016:95:e3963.

46 Mikkelsson LO, Nupponen H, Kaprio J, et al. Adolescent flexibility, endurance strength, and physical activity as predictors of adult tension neck, low back pain, and knee injury: a 25 year follow up study. Br J Sports Med 2006;40:107-13.

47 Jacobs JM, Hammerman-Rozenberg R, Cohen A, et al. Chronic back pain among the elderly: prevalence, associations, and predictors. Spine 2006;31:E203-E207.

48 Miranda H, Viikari-Juntura E, Punnett L, et al. Occupational loading, health behavior and sleep disturbance as predictors of low-back pain. Scand J Work Environ Health 2008;34:411-9.

49 Mattila VM, Saarni L, Parkkari J, et al. Predictors of low back pain hospitalization - a prospective follow-up of 57,408 adolescents. Pain 2008;139:209-17.

50 Hübscher M, Hartvigsen J, Fernandez $M$, et al. Does physical activity moderate the relationship between depression symptomatology and low back pain? Cohort and cotwin control analyses nested in the longitudinal study of aging Danish twins (LSADT). Eur Spine J 2016;25:1226-33.

51 Nilsen TI, Holtermann A, Mork PJ. Physical exercise, body mass index, and risk of chronic pain in the low back and neck/shoulders: longitudinal data from the NordTrondelag Health Study. Am J Epidemio/ 2011;174:267-73.

52 Makris UE, Fraenkel L, Han L, et al. Risk factors for restricting back pain in olde persons. J Am Med Dir Assoc 2014;15:62-7.

53 Leino-Arjas P, Solovieva S, Kirjonen J, et al. Cardiovascular risk factors and low-back pain in a long-term follow-up of industrial employees. Scand J Work Environ Health 2006;32:12-19.

54 Shiri R, Solovieva S, Husgafvel-Pursiainen K, et al. The role of obesity and physical activity in non-specific and radiating low back pain: the Young Finns Study. Semin Arthritis Rheum 2013;42:640-50.

55 Wedderkopp N, Kjaer P, Hestbaek L, et al. High-level physical activity in childhood seems to protect against low back pain in early adolescence. Spine J 2009;9:134-41.

56 Yip VY. New low back pain in nurses: work activities, work stress and sedentary lifestyle. J Adv Nurs 2004:46:430-40.

57 Strøyer J, Jensen LD. The role of physical fitness as risk indicator of increased low back pain intensity among people working with physically and mentally disabled persons: a 30-month prospective study. Spine 2008;33:546-54. 
58 Armijo-Olivo S, Stiles CR, Hagen NA, et al. Assessment of study quality for systematic reviews: a comparison of the cochrane collaboration risk of bias tool and the effective public health practice project quality assessment tool: methodological research. J Eval Clin Pract 2012;18:12-18.

59 Wang Z. Converting odds ratio to relative risk in cohort studies with partial data information. J Stat Softw 2013;55.

60 Higgins J, Green S. Cochrane Handbook for Systematic Reviews of Interventions Version 5.1.0 [updated March 2011]. The Cochrane Collaboration, 2009. www. cochrane-handbook.org. (accessed Mar 2017).

61 Borenstein M, Hedges L, Higgins J, et al. Introduction to meta-analysis. New York: John Wiley \& Sons, Ltd, 2009.

62 Higgins JP, Thompson SG. Quantifying heterogeneity in a meta-analysis. Stat Med 2002:21:1539-58.

63 Ioannidis JP, Patsopoulos NA, Evangelou E. Uncertainty in heterogeneity estimates in meta-analyses. BMJ 2007;335:914-6.

64 Morton SC, Adams JL, Suttorp MJ, et al. Meta-regression Approaches: What, Why, When, and How? Technical Review 8 (Prepared by Southern California-RAND Evidence-based Practice Center). Santa Monica, California 2004.

65 Rothstein H, Sutton A, Borenstein M. Publication bias in meta-analysis: prevention, assessment and adjustments: Wiley, 2005.

66 Duval S, Tweedie R. Trim and fill: a simple funnel-plot-based method of testing and adjusting for publication bias in meta-analysis. Biometrics 2000;56:455-63.

67 Burdorf A, Van Der Steenhoven GA, Tromp-Klaren EG. A one-year prospective study on back pain among novice golfers. Am J Sports Med 1996;24:659-64.

68 Steiger F, Wirth B, de Bruin ED, et al. Is a positive clinical outcome after exercise therapy for chronic non-specific low back pain contingent upon a corresponding improvement in the targeted aspect(s) of performance? A systematic review. Eur Spine J 2012;21:575-98.

69 Wong AY, Parent EC, Funabashi M, et al. Do changes in transversus abdominis and lumbar multifidus during conservative treatment explain changes in clinical outcomes related to nonspecific low back pain? A systematic review. J Pain 2014;15:377. e1-377.e35.

70 Halliday MH, Pappas E, Hancock MJ, et al. A randomized controlled trial comparing the McKenzie method to motor control exercises in people with chronic low back pain and a directional preference. J Orthop Sports Phys Ther 2016;46:514-22.
71 Smeets RJ, Vlaeyen JW, Kester AD, et al. Reduction of pain catastrophizing mediates the outcome of both physical and cognitive-behavioral treatment in chronic low back pain. J Pain 2006;7:261-71.

72 Mannion AF, Junge A, Taimela $S$, et al. Active therapy for chronic low back pain: part 3. factors influencing self-rated disability and its change following therapy. Spine 2001;26:920-9.

73 Kamper SJ, Apeldoorn AT, Chiarotto A, et al. Multidisciplinary biopsychosocial rehabilitation for chronic low back pain: Cochrane systematic review and metaanalysis. BMJ 2015;350:h444.

74 Schneider S, Becker S. Prevalence of physical activity among the working population and correlation with work-related factors: results from the first German National Health Survey. J Occup Health 2005;47:414-23.

75 Harvey SB, Hotopf M, Overland S, et al. Physical activity and common mental disorders. Br J Psychiatry 2010;197:357-64.

76 Griffith LE, Shannon HS, Wells RP, et al. Individual participant data meta-analysis of mechanical workplace risk factors and low back pain. Am J Public Health 2012;102:309-18.

77 Pinheiro MB, Ferreira ML, Refshauge K, et al. Symptoms of depression and risk of new episodes of low back pain: a systematic review and meta-analysis. Arthritis Care Res 2015;67:1591-603.

78 Strath SJ, Kaminsky LA, Ainsworth BE, et al. Guide to the assessment of physical activity: clinical and research applications: a scientific statement from the American Heart Association. Circulation 2013;128:2259-79.

79 Prince SA, Adamo KB, Hamel ME, et al. A comparison of direct versus self-report measures for assessing physical activity in adults: a systematic review. Int J Behav Nutr Phys Act 2008; 5:56.

80 van Weering MG, Vollenbroek-Hutten MM, Hermens HJ. The relationship between objectively and subjectively measured activity levels in people with chronic low back pain. Clin Rehabil 2011;25:256-63.

81 Schaller A, Rudolf K, Dejonghe L, et al. Influencing factors on the overestimation of self-reported physical activity: a cross-sectional analysis of low back pain patients and healthy controls. Biomed Res Int 2016;2016:1-11. 